\title{
Respiratory Mycoses: A Call to Action to Recognize, Educate and Invest
}

\author{
Anand Shah (1) - Darius Armstrong-James • Sanjay H. Chotirmall (D)
}

Received: 12 August 2021/ Accepted: 21 August 2021 / Published online: 7 September 2021

(C) The Author(s), under exclusive licence to Springer Nature B.V. 2021

\begin{abstract}
Although most of the $\sim 5$ million fungi in the natural world do not cause human infection, medical progress and anthropogenic factors over the last century have resulted in significant human populations developing susceptibility to fungally driven diseases [1]. Given the airborne dispersal of conidia within the fungal life cycle, the respiratory tract is a primary site of exposure [2]. Consequentially, we have observed a continued global increase in the burden of respiratory mycoses
\end{abstract}

\section{A. Shah $(\bowtie) \cdot$ D. Armstrong-James}

Department of Respiratory Medicine, Royal Brompton Hospital, Guy's and St. Thomas' NHS Foundation Trust, London, UK

e-mail: s.anand@imperial.ac.uk

A. Shah

MRC Centre of Global Infectious Disease Analysis, Department of Infectious Disease Epidemiology, School of Public Health, Imperial College London, London, UK

\section{Armstrong-James}

Faculty of Medicine, Department of Infectious Disease, Imperial College London, London, UK

\section{Armstrong-James}

MRC Centre for Molecular Bacteriology and Infection, London, UK

\section{S. H. Chotirmall}

Lee Kong Chian School of Medicine, Nanyang

Technological University, Singapore, Singapore over the last century that advocates recognition, education, and investment [3].

Despite some recognition, the overall global prevalence of respiratory mycoses is unclear. The coevolution of fungal pathogenicity with the development of cognate innate pattern-recognition receptors, such as the Toll-like receptors and C-type lectins, and fungal-specific adaptive immune responses, has resulted in increased complexity in the presentation of respiratory mycoses. These presentations range from sensitization through to invasive disseminated infection, across a myriad of populations and susceptibility states [4]. Alongside the recognition of fungal infection post-influenza, the COVID-19 pandemic has clearly highlighted the increasing burden and relevance of fungal infection across the spectrum of severe viral infection including Influenza-associated pulmonary aspergillosis, COVID-19-associated pulmonary aspergillosis (CAPA) and COVID-19associated mucormycosis $[5,6]$. The impact of fungal sensitization on driving exacerbations in chronic lung disease has only recently been realized, whilst the prevalence of chronic pulmonary aspergillosis in high and low tuberculosis prevalence settings remains under-reported due to misdiagnosis [3,7-12]. Despite advances in antifungal therapy, mortality and morbidity from acute and chronic respiratory mycoses including endemic mycoses such as Talaromycosis remain unacceptably high $[13,14]$. 
Compared to bacterial, viral, and parasitic research, funding for research into fungal disease and in particular respiratory mycoses remains low which translates into knowledge gaps, delays to research progress and therapeutic innovation [15]. To address this, we must recognize respiratory mycoses as an important clinical issue, educate physicians and the public and ensure healthcare systems are designed to optimize their detection and offer treatment. In this special issue, focused on respiratory mycoses, we outline the current knowledge base in this evolving field and present novel state-of-the-art future directions for clinical care and research aiming to improve outcomes in this neglected field.

The diagnosis of fungal infection in most areas around the world remains based on traditional culture, techniques dependant on operator expertise with poor yield and slow turn-around times resulting in delayed diagnosis, late implementation of appropriate therapy and increased mortality. The global implementation of rapid molecular diagnostics for tuberculosis as a direct result of focused coordinated research investment highlights such potential for the future advancement of fungal diagnostics [16]. The parallels with tuberculosis also extend to the global emergence of azole resistant Aspergillus fumigatus [17]. Clinical fungal disease, however, should be differentiated from the established resident respiratory mycobiome, where the detection and presence of fungal species do not necessarily indicate infection or related pathology [18]. In this issue, we detail how advances in mycobiome sequencing technologies and their corresponding bioinformatics pipelines have developed, alongside the recognition of Immunoglobulin E ( $\operatorname{IgE}$ ) sensitization to thermotolerant fungi in the context of acute and chronic respiratory mycoses, and present novel insight into endo-phenotyping approaches to stratify therapy [19-23] (Rhodes et al. Fungal genomics in respiratory medicine: How, what and when? MYCO-D-21-00072R1). To date, next-generation molecular mycobiome sequencing and wider fungal IgE sensitization testing remains a research tool and funding well-designed prospective longitudinal studies assessing impact and value in clinical settings combined with the development of low-cost rapid technology for deployment at scale, particularly in low- and middle-income countries where fungal burden is high, will be necessary to move the field forward.
In addition to rapid molecular resistance analysis to enable appropriate therapy, an optimisation of current antimicrobial fungal therapy through implementation of stewardship programmes is key in the fight against antimicrobial resistance [24]. The burden of antifungal resistance is markedly higher in those with chronic respiratory mycoses, yet in this issue we show that implementation of antifungal stewardship is widely neglected [25]. As an undoubted reservoir of antifungal resistance evolution, greater attention from the infectious disease and respiratory communities that oversee such initiatives is necessary as are investment from major funding bodies to drive implementation science in this setting.

The diagnosis of respiratory mycoses is often highly dependent on the integration of clinical and radiological features in combination with serological and microbiological results, with clinical expertise and experience dictating diagnostic certainty. However, the last few years have seen the rapid emergence of machine learning tools to reduce such diagnostic uncertainty and provide prognostic guidance [26]. Big data approaches are, however, dependent on the development of well curated, pseudo-anonymised electronic health record and imaging datasets available for the research community through international networks and collaboration [27]. Within the field of respiratory mycoses, this presents an opportunity for recently developed clinical research collaborations including CPA-net (chronic pulmonary aspergillosis research network) and EMBARC (The European bronchiectasis network) among others [28-30].

Like other infectious pathogens, an increased burden of respiratory mycoses exists in low- and middle-income countries [31]. The reasons are often complex and relate to the higher prevalence of immunocompromised states in the setting of untreated HIV for example, increased tuberculosis, and high rates of chronic lung disease related to smoking, occupational lung disease, biofuel exposure and air pollution. In addition, climate change contributes to the increasing prevalence of warm humid environments, ideal for fungal propagation and exposure to zoonotic reservoirs of infection further increase prevalence [32]. In this issue, we highlight recent advances of endemic myoses such as Cryptococcosis, Histoplasmosis and Talaromycosis, including the inaugural Mycopathologia PROFILE article addressing Cryptococcus [14, 33, 34] (also Gomez et al. 
Pulmonary Histoplasmosis, MYCO-D-21-00075). Although significant breakthroughs have been made in this latter field, therapies for endemic mycoses continue to remain hampered by the lack of accessible molecular diagnostics, and the absence of a solid evidence base for treatment efficacy.

Despite inherent challenges, optimism remains strong in the current pipeline of antifungal therapeutics, with several compounds in late phase clinical trials that have been reviewed in this issue [35]. Phase 3 clinical trials often focus on specific populations of carefully selected invasive fungal disease, which represents only a proportion of the respiratory mycoses burden globally. As discussed in this issue (Armstrong-James et al. Future directions for clinical respiratory fungal research, MYCO-D-21-00055), a challenge for the respiratory mycoses and pharmaceutical communities are to ensure that novel antifungal compounds are trialled across the disease spectrum and by need, alongside continuing trials of existing antifungals in disease areas currently outside their licensing indications. The COVID-19 pandemic has highlighted the impact of well-designed, adaptive clinical trial platforms within infectious disease and provides a template for the fungal community moving forward.

An improved understanding of chronic lung disease immunopathogenesis has excitingly started to translate to novel therapeutic approaches as seen with small molecule therapies in Cystic Fibrosis (e.g. Elexacaftor-Tezacaftor-Ivacaftor), novel immune pathway targeted therapies such as anti-IL-5 (e.g. benralizumab) in asthma or COPD and neutrophil elastase inhibitors (e.g. brensocatib) in bronchiectasis [36-39]. As detailed in this issue, such novel therapeutics will invariably influence the host immune response to fungi $[40,41]$. As such, it is critical for clinicians and the pharmaceutical industry to ensure that prospective clinical trials and post-licensing registry studies capture such impact on fungal disease to adequately inform safe therapeutic decision making.

In summary, as editors of this special issue on Respiratory Mycoses, we aim to bring focus and recognition to this rising epidemic of disease burden and, hope to spotlight the emerging science and highlight critical knowledge and translational gaps to encourage the fungal community and funding agencies to invest time, effort and resources in shaping the clinical, pharmaceutical, and governmental policies in tackling this relatively neglected area of medicine.

Author Contribution AS, DAJ and SC co-wrote the editorial piece.

Funding AS is supported by a MRC Clinical Academic Research Partnership award MRC; MR/TOO5572/1 and by the MRC centre grant MRC; MR/R015600/1.

\section{Declarations}

Conflict of interest AS reports research grants from Vertex pharmaceuticals, Pfizer and Gilead Sciences and speaker fees from Pfizer and Gilead Sciences.

\section{References}

1. Casadevall A, Pirofski L. The damage-response framework of microbial pathogenesis. Nat Rev Microbiol [Internet]. Nature Publishing Group; 2003 [cited 2021 Aug 8];1:17. / pmc/articles/PMC7097162/

2. Denning DW, Chakrabarti A. Pulmonary and sinus fungal diseases in non-immunocompromised patients. Lancet Infect Dis [Internet]. Elsevier; 2017 [cited 2021 Aug 8];17:e357-66. http://www.thelancet.com/article/ S1473309917303092/fulltext

3. Vallabhaneni S, Mody R, Walker T, Chiller T. The global burden of fungal diseases. Infect Dis Clin North Am. 2016;30:1-11.

4. Köhler JR, Hube B, Puccia R, Casadevall A, Perfect JR. Fungi that Infect Humans. Microbiol Spect [Internet]. American Society for Microbiology; 2017 [cited 2021 Aug 8];5. https://journals.asm.org/journal/spectrum

5. Armstrong-James D, Youngs J, Bicanic T, Abdolrasouli A, Denning DW, Johnson E, et al. Confronting and mitigating the risk of COVID-19 associated pulmonary aspergillosis. Eur Resp J [Internet]. European Respiratory Society; 2020 [cited 2021 Aug 11];56. /pmc/articles/PMC7377212/

6. Selarka L, Sharma S, Saini D, Sharma S, Batra A, Waghmare VT, et al. Mucormycosis and COVID-19: An epidemic within a pandemic in India. Mycoses [Internet]. Wiley; 2021 [cited 2021 Aug 11]; https://onlinelibrary.wiley.com/doi/full/https://doi.org/10.1111/myc.13353

7. Tiew PY, Dicker AJ, Keir HR, Poh ME, Pang SL, Aogáin M mac, et al. A high-risk airway mycobiome is associated with frequent exacerbation and mortality in COPD. Eur Resp J [Internet]. European Respiratory Society; 2021 [cited 2021 Aug 8];57. https://erj.ersjournals.com/content/57/3/ 2002050

8. mac Aogáin M, Narayana JK, Tiew PY, Ali NABM, Yong VFL, Jaggi TK, et al. Integrative microbiomics in bronchiectasis exacerbations. Nat Med 2021 27:4 [Internet]. Nature Publishing Group; 2021 [cited 2021 Aug 8];27:688-99. https://www.nature.com/articles/s41591021-01289-7 
9. Tiew PY, Lim AYH, Keir HR, Dicker AJ, Aogáin M mac, Pang SL, et al. High frequency of allergic Bronchopulmonary aspergillosis in bronchiectasis-copd overlap. Chest [Internet]. Elsevier; 2021 [cited 2021 Aug 9];0. http:// journal.chestnet.org/article/S0012369221036205/fulltext

10. Aogáin M mac, Tiew PY, Lim AYH, Low TB, Tan GL, Hassan T, et al. Distinct "Immunoallertypes" of Disease and High Frequencies of Sensitization in Non-Cystic Fibrosis Bronchiectasis. Doi:https://doi.org/10.1164/ rccm201807-1355OC [Internet]. American Thoracic Society; 2019 [cited 2021 Aug 11];199:842-53. www. atsjournals.org.

11. Connell D, Shah A. The contribution of Aspergillus fumigatus to COPD exacerbations: a "sensitive" topic. European Respiratory Journal. European Respiratory Society; 2020;56.

12. Tiew PY, Ko FWS, Pang SL, Matta SA, Sio YY, Poh ME, et al. Environmental fungal sensitisation associates with poorer clinical outcomes in COPD. Eur Resp J [Internet]. European Respiratory Society; 2020 [cited 2021 Aug 11];56. /pmc/articles/PMC7453645/

13. Maitre T, Cottenet J, Godet C, Roussot A, Carime NA, Ok V, et al. Chronic Pulmonary Aspergillosis: Prevalence, favouring pulmonary diseases and prognosis. Eur Resp J [Internet]. European Respiratory Society; 2021 [cited 2021 Aug 8];2003345. https://erj.ersjournals.com/content/early/ 2021/01/14/13993003.03345-2020

14. Narayanasamy S, Dougherty J, van Doorn HR, Le T. Pulmonary Talaromycosis: A Window into the Immunopathogenesis of an Endemic Mycosis. Mycopathologia 2021 [Internet]. Springer; 2021 [cited 2021 Aug 8];1-9. https://link.springer.com/article/https://doi.org/10. 1007/s11046-021-00570-0

15. Rodrigues ML, Nosanchuk JD. Fungal diseases as neglected pathogens: A wake-up call to public health officials. PLoS Neglected Tropical Diseases [Internet]. Public Library of Science; 2020 [cited 2021 Aug 8];14. /pmc/articles/ PMC7032689/

16. Furin J, Cox H, Pai M. Tuberculosis Lancet. 2019;393:1642-56.

17. Fisher MC, Hawkins NJ, Sanglard D, Gurr SJ. Worldwide emergence of resistance to antifungal drugs challenges human health and food security. Science [Internet]. American Association for the Advancement of Science; 2018 [cited 2021 Aug 8];360:739-42. https://science. sciencemag.org/content/360/6390/739

18. Ali NA tikah BM, Ivan FX, mac Aogáin M, Narayana JK, Lee SY, Lim CL, et al. The healthy airway mycobiome in individuals of Asian descent. Chest. 2021;159:544-8.

19. Tiew PY, mac Aogáin M, Ter SK, Aliberti S, Chalmers JD, Chotirmall SH. Respiratory Mycoses in COPD and Bronchiectasis. Mycopathologia. 2021

20. Yan G, Chew KL, Chai LYA. Update on non-culture-based diagnostics for invasive fungal disease. Mycopathologia. 2021

21. Pashley $\mathrm{CH}$, Wardlaw AJ. Allergic fungal airways disease (AFAD): an under-recognised asthma endotype. Mycopathologia. 2021

22. Sio YY, Pang SL, Say YH, Teh KF, Wong YR, Shah SMR, et al. Sensitization to airborne fungal allergens associates with asthma and allergic rhinitis presentation and severity in the Singaporean/Malaysian population. Mycopathologia. 2021

23. Jaggi TK, Ter SK, Aogáin M mac, Chotirmall SH. Aspergillus-Associated Endophenotypes in Bronchiectasis. Semin Resp Crit Care Med [Internet]. Thieme Medical Publishers, Inc.; 2021 [cited 2021 Aug 9];42:556-66. http:// www.thieme-connect.com/products/ejournals/html/https:// doi.org/10.1055/s-0041-1730947

24. Goff DA, Kullar R, Goldstein EJC, Gilchrist M, Nathwani $\mathrm{D}$, Cheng AC, et al. A global call from five countries to collaborate in antibiotic stewardship: united we succeed, divided we might fail. Lancet Infect Dis. 2017;17:e56-63.

25. Aldossary S, Shah A. Healthcare utilization and impact of antifungal stewardships within respiratory care settings: a systematic literature review. Mycopathologia. 2021

26. Angelini E, Dahan S, Shah A. Unravelling machine learning: insights in respiratory medicine. Eur Resp J [Internet]. European Respiratory Society; 2019 [cited 2021 Aug 8];54. https://erj.ersjournals.com/content/54/6/1901216

27. Chotirmall SH, Dahlén S-E, Carlsten C, Wong WSF, Chung $\mathrm{KF}$, Gosens R, et al. International research collaboration: The way forward. Respirology [Internet]. Wiley; 2018 [cited 2021 Aug 9];23:654-5. https://onlinelibrary.wiley.com/doi/full/https://doi.org/10.1111/resp.13327

28. Angelini E, Shah A. Using artificial intelligence in fungal lung disease: CPA CT imaging as an example. Mycopathologia. 2021

29. Laursen CB, Davidsen JR, van Acker L, Salzer HJF, Seidel $\mathrm{D}$, Cornely OA, et al. CPAnet registry - an international chronic pulmonary Aspergillosis registry. J Fungi 2020; 6:96 [Internet]. Multidisciplinary Digital Publishing Institute; 2020 [cited 2021 Aug 9];6:96. https://www.mdpi.com/ 2309-608X/6/3/96/htm

30. Chalmers JD, Crichton M, Goeminne PC, Loebinger MR, Haworth C, Almagro M, et al. The European Multicentre Bronchiectasis Audit and Research Collaboration (EMBARC): experiences from a successful ERS Clinical Research Collaboration. Breathe [Internet]. European Respiratory Society; 2017 [cited 2021 Aug 9];13:180. /pmc/ articles/PMC5584712/

31. Vallabhaneni S, Mody RK, Walker T, Chiller T. The global burden of fungal diseases. Infect Dis Clin $\mathrm{N}$ Am. 2016;30:1-11.

32. Friedman DZP, Schwartz IS. Emerging fungal infections: new patients, new patterns, and new pathogens. J Fungi [Internet]. Multidisciplinary Digital Publishing Institute (MDPI); 2019 [cited 2021 Aug 8];5. /pmc/articles/ PMC6787706/

33. Yamamura D, Xu J. Update on pulmonary cryptococcosis. Mycopathologia. 2021

34. Francisco EC, de Jong AW, Hagen F. Cryptococcosis and cryptococcus. Mycopathologia. 2021

35. Waterer G. Advances in anti-fungal therapies. Mycopathologia. 2021

36. Middleton PG, Mall MA, Dřevínek P, Lands LC, McKone EF, Polineni D, et al. Elexacaftor-Tezacaftor-Ivacaftor for cystic fibrosis with a single Phe508del Allele. Doi:101056/ NEJMoa1908639 [Internet]. Massachusetts Medical Society; 2019 [cited 2021 Aug 8];381:1809-19. https:// www.nejm.org/doi/https://doi.org/10.1056/ NEJMoa1908639 
37. Nair P, Wenzel S, Rabe KF, Bourdin A, Lugogo NL, Kuna $\mathrm{P}$, et al. Oral Glucocorticoid-Sparing Effect of Benralizumab in Severe Asthma. Doi:https://doi.org/10.1056/ NEJMoa1703501 [Internet]. Massachusetts Medical Society; 2017 [cited 2021 Aug 8];376:2448-58. https:// www.nejm.org/doi/https://doi.org/10.1056/ NEJMoa1703501

38. Criner GJ, Celli BR, Singh D, Agusti A, Papi A, Jison M, et al. Predicting response to benralizumab in chronic obstructive pulmonary disease: analyses of GALATHEA and TERRANOVA studies. Lancet Resp Med. 2020;8:158-70.

39. Chalmers JD, Haworth CS, Metersky ML, Loebinger MR, Blasi F, Sibila O, et al. Phase 2 Trial of the DPP-1 Inhibitor Brensocatib in Bronchiectasis. Doi:https://doi.org/10.1056/ NEJMoa2021713 [Internet]. Massachusetts Medical
Society; 2020 [cited 2021 Aug 11];383:2127-37. https:// www.nejm.org/doi/https://doi.org/10.1056/ NEJMoa2021713

40. Bercusson A, Jarvis G, Shah A. CF fungal disease in the age of CFTR Modulators. Mycopathologia. 2021

41. Schwarz C, Eschenhagen P, Bouchara JP. Emerging fungal threats in cystic fibrosis. Mycopathologia 2021 [Internet]. Springer; 2021 [cited 2021 Aug 9];1-15. https:// link.springer.com/article/https://doi.org/10.1007/s11046021-00574-w

Publisher's Note Springer Nature remains neutral with regard to jurisdictional claims in published maps and institutional affiliations. 